\title{
Attitudes of registered physiotherapists in Israel toward people identifying as lesbian, gay, and bisexual: a cross-sectional survey
}

Roei Klein and Michal Elboim-Gabyzon*

\begin{abstract}
Background: This study aimed to explore the attitudes of registered physiotherapists (PTs) in Israel toward people identifying as lesbian, gay, or bisexual (LGB) and to identify background characteristics associated with their attitudes toward LGB individuals.

Methods: This nationwide study in Israel employed an observational design. Participants completed an anonymous online questionnaire which included demographic characteristics (e.g., age, sex, gender, sexual orientation, religious affiliation, and religiousness) and questions regarding sources of knowledge about LGB individuals, and type of acquaintance with an LGB individual. In addition to two self-assessment questions regarding levels of homophobia (active engagement against LGB individuals) and heterosexism (holding negative opinions regarding LGB individuals) answered on a five point Likert scale (1 - not at all homophobic/ heterosexist, 5-very homophobic/ heterosexist) and the Hebrew version of the Attitudes Toward Homosexuality Scale (ATHS). Participants were recruited through professional organizations, social media, and word of mouth.
\end{abstract}

Results: The data of 383 registered PTs practicing in Israel were analyzed. The median score regarding level of homophobia and heterosexism was one ("not at all"). ATHS scores ranged between 32 and 110 (out of 110), with a median score of 106 and $41 \%$ scoring below the median. Multivariant logistic regression indicated that identifying as men, heterosexual orientation, and religiousness were significantly associated with less positive attitudes toward LGB individuals. Only $2 \%$ of the participants reported having been introduced to issues regarding the LGB community during their professional physiotherapy education.

Conclusions: Registered PTs in Israel demonstrated favorable attitudes toward LGB individuals, as reflected both by ATHS scores and levels of self-reported homophobia and heterosexism. Based on the current results regarding sources of knowledge, updating the physiotherapy curriculum to include information regarding sexual orientation and health of the LGB community is suggested.

Keywords: LGB, Attitudes, Physiotherapists, Sexual and gender minorities, Health-related quality of life, Curriculum, Heterosexuality

*Correspondence: michal.elboim@gmail.com

Physical Therapy Department, Faculty of Social Welfare and Health Sciences, University of Haifa, 199 Aba Khoushy Ave., Mount Carmel, (Eshkol Bldg., Floor 9, room 910), Haifa, Israel

\section{Background}

Sexual minorities often endure poorer physical, mental, and sexual health compared to heterosexual individuals [1]. People who identify as lesbian, gay, bisexual, transgender, or intersex (LGBTI) experience lifelong institutional and social discrimination in areas such 
as education, employment, recreational activities, and healthcare facilities and services [2, 3]. Stigmatization and derived negative attitudes toward LGBTI people are prevalent among the general population [4].

There is no consensus in the literature regarding the attitudes and behaviors of healthcare professionals toward sexual minorities. Some studies have reported positive and tolerant attitudes toward LGBTI people among healthcare professionals $[5,6]$. However, most studies show that healthcare professionals, such as physicians [7], nurses [7], dentists, mental health professionals $[6,7]$, athletic trainers [8], and social workers [7] do demonstrate varying degrees of sexual prejudice, negative attitudes, and biased care toward sexual minority patients. The nature of the attitudes may depend on the specific profession of the healthcare provider. For example, psychologists and social workers generally exhibit more positive attitudes toward LGBTI people $[7,9]$ compared to nurses and physicians $[7,10]$.

Only a few studies have focused on the attitudes of PTs toward LGBTI individuals [11-13]. Burch [11], who explored the attitudes of various health professionals toward individuals with spinal cord injuries, demonstrated that PTs $(N=176)$ generally exhibited attitudes of tolerance toward patients with diverse sexual orientations. Thus, while $1 \%$ of PTs stated that they "find it difficult to have respect" for LGBTI patients, and another $1 \%$ reported that they have "full respect," [11] most participants stated, "I have tolerance" and "some respect" (85 and 13\%, respectively). Ross and Setchell focused on the experiences of 108 patients who identify as LGBTI, queer, or related identitieswhile attending physiotherapy [13]. Almost all participants reported at least one of the following situations: erroneous assumptions by the PTs, feelings of discomfort, explicit and implicit discrimination, and a lack of knowledge of their specific health needs [13].

Health care of sexual and gender minorities, therapeutic encounters and cultural competency might be improved by integrating in the curriculum studies of health care professional issues relating the populationspecific needs of LGBTI [14]. In a survey exploring the integration of LGBTI-related topics in the curriculum of 229 Director of Physical Therapy programs in United States, it was determined that among $31 \%$ of respond, only half reported delivering one or more curricula hours per year on this topic [15]. In addition, the survey results indicate that the barriers to the teaching of LGBTI related topics are lack of time and lack of sufficient faculty training [15] .

Owing to the paucity of available information, we believe it is crucial to explore PTs' attitudes toward individuals identifying as LGB. Furthermore, it is important to understand the background characteristics of PTs which may relate to their attitudes. Understanding these issues may enhance our ability to promote cultural competence and unbiased care toward sexual minorities, thus promoting optimal physiotherapy care in accordance with accepted bioethical principles [16, 17].

The research questions were:

1. What are the attitudes of registered PTs in Israel toward people identifying as LGB?

2. What background characteristics of PTs relate to their attitudes toward LGB individuals?

\section{Methods \\ Design}

This study employed an observational design. An anonymous nationwide online self-report survey using Google Forms was conducted between September 2019 and March 2020. Accompanying online instructions indicated that completing and sending the questionnaire was indicative of informed consent. This study was approved by the Ethics Committee at the Faculty of Social and Health Sciences, at the University of Haifa (number 19/388).

\section{Participants}

Participant recruitment involved the use of social media avenues such as Facebook physiotherapy professional groups, the newsletter of the Israeli Physiotherapy Society, and word of mouth among PTs. All respondents were registered PTs in Israel. There were no restrictions regarding clinical experience and workplace.

\section{Outcome measures}

The following were the outcome measures:

1. A demographic questionnaire regarding sex, gender, age, education, place of residence, sexual orientation, professional experience, religious affiliation, and religiousness was used. It also included questions regarding sources of knowledge of LGB individuals (8 response options), knowing individuals within the LGB community (yes/no response) and types of acquaintance with an LGB individual (total of 7 options including nuclear family, distant social circle, etc.); see Table 2.

2. Two self-assessment questions regarding the individual's level of homophobia and heterosexism, measured on a five-point Likert scale ranging from one (not at all homophobic/heterosexist) to five (very homophobic/heterosexist). Definitions of the two terms were based on Ben-Ari's [18] paper and were provided in the survey to ensure that participants 
understood these terms. Thus, "homophobic" was defined as a person who actively acts against members of the LGB community, and "heterosexist" was defined as a person who holds negative opinions regarding LGB community members but does not actively act against them [18].

3. Attitudes were evaluated using the Hebrew version of the Attitudes Toward Homosexuality Scale (ATHS), originally developed by Kite and Deux [19]. The ATH scale is the only validated and reliable tool in Hebrew focusing on attitudes toward homosexuality. The Hebrew version has previously demonstrated good psychometric properties (internal consistency, Cronbach's alpha $=0.93$, and good test-retest reliability $(r=.71))[20,21]$. These results are compatible with the original version. The Hebrew version of the ATHS includes 22 statements (see Table 3 ) regarding attitudes toward homosexuality rated on a five-point Likert-type scale ranging from one ("strongly agree") to five ("strongly disagree"). The overall score ranges from 22 to 110 in the Hebrew version, compared to 21 to 105 in the English version (the Hebrew version includes an additional question (question 22) about acquired immunodeficiency syndrome (AIDS). A higher score on the scale indicates more positive attitudes toward the LGB community. Answers to items $1,2,6,8,13,14,15,18,19,20$, and 21 are reverse scored. To the best of our knowledge, there is no cutoff value of the ATHS defining the level of negative/ positive attitudes toward homosexuality.

\section{Data analysis}

Descriptive statistics were calculated for personal characteristics of participants, knowledge source and acquaintance with LBG individuals, heterosexism and homophobia levels, and for the results of the ATHS.

Since the distribution of the response score by the participants on the dependent variables (heterosexism levels and for the results of the ATHS) were not uniform along the possible scores, we categorized it for the purpose of further statistical analyses (group comparisons and logistic regression analysis).

The ATHS score, the values were not distributed in an even pattern across the possible ranges of 22 to 110 . The majority of participants (over $80 \%$ ) answered a value higher than 100.

Accordingly, the median score (106) of the ATHS variable was defined as the cutoff point and converted into a categorical score. Scores above or equal to the median response of the sample $(\geq 106)$ were one category, and scores below the median $(<106)$ were the second category.Comparisons analysis between categorical variables were performed using the Chi-square test and were reported as numbers and percentages (\%). This analysis explored the relationships between the categorical outcome measures (sex, gender, educational level, place of residence, and sexual orientation), the ATHS score, and the level of heterosexism.

Results regarding age and years of experience as a PTs were normally distributed. Between-group comparisons of ATHS scores for these variables were performed using the $\mathrm{t}$-test and univariate analysis of variance (ANOVA) for the level of heterosexism. The level of religiousness was non-normally distributed, and group comparisons were performed using the Wilcoxon rank-sum test for the ATHS score and the Kruskal-Wallis test for the level of heterosexism.

Multivariate logistic regression analysis was used for the prediction of positive attitudes toward Homosexuality (total ATHS score $\geq 106$ ) by gender, age, sexual orientation, religiousness, years of experience, educational level, and place of residence. Odds Ratio value above value 1 indicates more positive attitudes.

Significance was established at $p$-values $\leq 0.05$.

\section{Results \\ Participants}

The study sample included 383 registered PTs (average age $39.1 \pm 9.1$ years), with $76 \%$ females and $90 \%$ identifying as heterosexual. Two participants identified as transgender. Most respondents were Jewish (94\%). Overall, $74 \%$ identified as secular, $14 \%$ as traditional, and $12 \%$ as religious. Further details on participants' personal characteristics are presented in Table 1. Details on source of information regarding the LGB community as well as venues of acquaintance are detailed in Table 2 . The majority of respondents $(66 \%)$ reported that the source of their knowledge was the media (e.g., social media, television, newspapers). Only $2 \%$ of the respondents reported having been introduced to this topic during their professional physiotherapy bachelor's or master's degrees. Most of the PTs reported pervious acquaintance with an individual identifying as LGB (97\%). The most common types of acquaintance were through distant social circles (70\%) or at work/school/academy (75\%).

Research question 1: PTs' attitudes toward LGB individuals.

Table 3 \& Table 4 delineates the results of both the questions regarding levels of homophobia, heterosexism and the ATHS scale.

The median level of homophobia score was one out of five, indicating extremely low levels of homophobia. The distribution of the answers in the five-point Likert was unequal across the scale, with $89 \%$ scoring one (not at all homophobic) and 8\% scoring two. Accordingly, this 
Table 1 Personal characteristics of participants

\begin{tabular}{|c|c|}
\hline Characteristics & Participants $(N=383)$ \\
\hline Age, years, mean $\pm S D$, range & $39.1 \pm 9.1,23-69$ \\
\hline Sex, n (\%): Male; Female & $91(24) ; 292(76)$ \\
\hline Gender, $\mathrm{n}(\%)$ : Men; Women & $93(24) ; 290(76)$ \\
\hline \multicolumn{2}{|l|}{ Sexual orientation, $\mathrm{n}(\%)$} \\
\hline Heterosexual & $346(90)$ \\
\hline Lesbian, gay, and bisexual & $37(10)$ \\
\hline \multicolumn{2}{|l|}{ Educational level, n (\%) } \\
\hline Bachelor's degree & $260(68)$ \\
\hline Master's degree & $111(29)$ \\
\hline Doctorate & $12(3 \%)$ \\
\hline \multicolumn{2}{|l|}{ Religion } \\
\hline Judaism & $358(94)$ \\
\hline Islam & $7(2)$ \\
\hline Christianity & $14(4)$ \\
\hline Atheist & $3(1)$ \\
\hline Missing & $1(0.3)$ \\
\hline \multicolumn{2}{|l|}{ Religiousness } \\
\hline Secular & $284(74)$ \\
\hline Traditional & $54(14)$ \\
\hline Religious & $45(12)$ \\
\hline Work experience, years, mean $\pm S D$, range & $12.3 \pm 9.4,0.5-44$ \\
\hline \multicolumn{2}{|l|}{ Place of work, $n(\%)^{a}$} \\
\hline Public outpatient care & $163(37)$ \\
\hline Private outpatient care & $167(44)$ \\
\hline Acute hospital & $54(14)$ \\
\hline Rehabilitation hospital & $70(18)$ \\
\hline Child development & $74(19)$ \\
\hline Academia & $25(7)$ \\
\hline Senior citizens' homes & $18(5)$ \\
\hline Others & $29(8)$ \\
\hline \multicolumn{2}{|l|}{ Place of residence $\mathbf{n}(\%)$} \\
\hline Urban & $244(64)$ \\
\hline Other forms of residence (Village, Kibbutz, etc.) & $139(36)$ \\
\hline
\end{tabular}

SD: standard deviation

a can exceed $100 \%$

outcome measure was not included in further statistical analyses (group comparisons and logistic regression analysis).

The median level of heterosexism score was one out of five, indicating extremely low levels of heterosexism. The distribution of the answers regarding heterosexism level were more balanced compared to the level of homophobia with $62.4 \%$ indicating a score of 1 , and remaining distributed along the scale (for details see Table 3). Thus, the level of heterosexism was categorized as low (scores $1-2$ ), medium (score 3), and high (scores 4-5).

The median ATHS score was 106 out of 110 indicating favorable attitudes toward LGB individuals. Scores
Table 2 Knowledge source and acquaintance with lesbian, gay, and bisexual individuals of 383 registered physiotherapists, $n$ (\%)

\begin{tabular}{ll}
\hline Characteristic & $\begin{array}{l}\text { Participants } \\
\text { number } \\
\text { (percentage) }\end{array}$ \\
\hline $\begin{array}{l}\text { Sources of knowledge } \\
\text { Have no knowledge on the topic }\end{array}$ & $8(2 \%)$ \\
Bachelor's degree in physiotherapy & $5(1 \%)$ \\
Master's degree in physiotherapy & $5(1 \%)$ \\
Academic studies, not in physiotherapy & $7(2 \%)$ \\
Non-academic studies & $22(6 \%)$ \\
Personal interest & $215(56 \%)$ \\
Media (e.g., social media, television, newspapers) & $254(66 \%)$ \\
Personal acquaintance & $301(79 \%)$ \\
Acquaintance with an individual identifying as LGB & \\
Yes & $372(97 \%)$ \\
No & $11(3 \%)$ \\
Type of acquaintance with an LGB individual & \\
Nuclear family & \\
Extended family & $48(13 \%)$ \\
Close social circle & $116(30 \%)$ \\
Distant social circle & $178(47 \%)$ \\
Patient(s) & $268(70 \%)$ \\
Work, school, academy & $161(42 \%)$ \\
Other & $286(75 \%)$ \\
\hline
\end{tabular}

LGB: lesbian, gay, and bisexual

${ }^{a}$ can exceed $100 \%$

Table 3 Descriptive statistics of heterosexism and homophobia levels (Median, IQR, Distribution per Likert scale; number of respondents (percentage) $(\mathrm{N}=383)$

\begin{tabular}{ll}
\hline Variable & \\
\hline $\begin{array}{l}\text { Total score regarding heterosexism: Median (IQR) } \\
\text { Distribution per Likert scale; number of respondents }\end{array}$ & $1.0(1.0,3.0)$ \\
(percentage) & $239(62.4 \%)$ \\
Level 1 (not at all) & $29(7.57 \%)$ \\
Level 2 & $32(8.36 \%)$ \\
Level 3 & $27(7.05 \%)$ \\
Level 4 & $56(14.62 \%)$ \\
Level 5 (very) & $1.0(1.0,1.0)$ \\
Total score regarding homophobia: Median (IQR) & \\
Distribution per Likert scale; number of respondents & \\
(percentage) & $342(89.3 \%)$ \\
Level 1 (not at all) & $29(7.57 \%)$ \\
Level 2 & $8(2.09 \%)$ \\
Level 3 & $1(0.26 \%)$ \\
Level 4 & $3(0.78 \%)$ \\
Level 5 (very) &
\end{tabular}


Table 4 The results of the Attitudes Toward Homosexuality Scale (Median; range; IQR) $(N=383)$

\begin{tabular}{|c|c|}
\hline Variable & Median; range; (IQR) \\
\hline \multicolumn{2}{|l|}{ Attitudes Toward Homosexuality Scale } \\
\hline Total Attitudes Toward Homosexuality Scale score & $106 ; 32.00-110.00(102-109)$ \\
\hline 1. I would not mind having homosexual friends. & $5 ; 1-5(5-5)$ \\
\hline 2. Finding out that an artist was gay would have no effect on my appreciation of his/her work. & $5 ; 1-5(5-5)$ \\
\hline 3. I would not associate with known homosexuals if I can help it. & $5 ; 1-5(5-5)$ \\
\hline 4. I would look for a new place to live if I found out my roommate was gay. & $5 ; 1-5(5-5)$ \\
\hline 5. Homosexuality is a mental illness. & $5 ; 1-5(5-5)$ \\
\hline 6. I would not be afraid for my child to have a homosexual teacher. & $5 ; 1-5(5-5)$ \\
\hline 7. Gays dislike members of the opposite sex. & $5 ; 1-5(5-5)$ \\
\hline 8. I do not really find the thought of homosexual acts disgusting. & $5 ; 1-5(3-5)$ \\
\hline $\begin{array}{l}\text { 9. Homosexuals are more likely to commit deviant sexual acts, such as child molestation, rape, and voyeurism (peeping } \\
\text { Toms), than are heterosexuals. }\end{array}$ & $5 ; 1-5(5-5)$ \\
\hline 10. Homosexuals should be kept separate from the rest of society (i.e., separate housing, restricted employment). & $5 ; 1-5(5-5)$ \\
\hline 11. Two individuals of the same sex holding hands or displaying affection in public is revolting. & $5 ; 1-5(5-5)$ \\
\hline 12. The love between two males or two females is quite different from the love between two persons of the opposite sex. & 5.; $1-5(4-5)$ \\
\hline 13. I see the gay movement as a positive thing. & $5 ; 1-5(4-5)$ \\
\hline 14. Homosexuality, as far as I'm concerned, is not sinful. & $5 ; 1-5(5-5)$ \\
\hline 15. I would not mind being employed by a homosexual. & $5 ; 1-5(5-5)$ \\
\hline 16. Homosexuals should be forced to have psychological treatment. & $5 ; 1-5(5-5)$ \\
\hline 17. The increasing acceptance of homosexuality in our society is aiding in the deterioration of morals. & $5 ; 1-5(5-5)$ \\
\hline 18. I would not decline membership in an organization just because it has homosexual members. & $5 ; 1-5(5-5)$ \\
\hline 19. I would vote for a homosexual in an election for public office. & $5 ; 1-5(5-5)$ \\
\hline 20. If I knew someone were gay, I would still go ahead and form a friendship with that individual. & $5 ; 1-5(5-5)$ \\
\hline 21. If I were a parent, I could accept my son or daughter being gay. & $5 ; 1-5(4-5)$ \\
\hline 22. Homosexuals are guilty of spreading AIDS. & $5 ; 1-5(4-5)$ \\
\hline
\end{tabular}

Notes: We used the validated Hebrew version but are presenting here the original English questions; questions 1, 2, 6, 8, 13, 14, 15, 18, 19, 20, and 21 were reverse scored. Question 22 was added and validated for the Hebrew version of the questionnaire

IQR: interquartile range, SD: standard deviation; AIDS: acquired immunodeficiency syndrome

ranged between 32 and 110 , with $41 \%$ scoring below the median.

Research question 2: Relation of background characteristics with PTs' attitudes.

The results of the relation of different background characteristics with levels of heterosexism as well as the ATHS scores are presented in Table 5.

Males and men demonstrated significantly less favorable attitudes toward homosexuality, as reflected by the higher levels of heterosexism and the number/percentage of participants scoring below the median on the ATHS, as compared to females and women $(17 \%$ males versus $83 \%$ females for $>106$ on the ATHS) Conversely, age, educational level, years of experience, and place of residence made no difference in the participants' attitudes toward LGB individuals based on analyses for heterosexism level question or the ATHS scores. Participants belonging to sexual and gender minority groups had more positive attitudes toward LGB people (87\% not LGB versus $13 \%$ LGB for $>106$ on the ATHS). Individuals identifying as secular demonstrated more positive attitudes than traditional and religious individuals $(87 \%$ secular versus $13 \%$ traditional and religious for $>106$ on the ATHS).

Logistic regression results indicated that gender, sexual orientation, and religiousness significantly predicted attitudes toward LGB individuals, as reflected in the ATHS scores; for details, see Table 6. Woman, non-heterosexual orientation, and secularity and being traditional were predictors of positive attitudes toward LGB individuals (ATHS value $\geq 106$ ). The probability of women achieving ATHS value $\geq 106$ was 4.11 times greater than the probability of men (OR 4.11, 95\% CI 2.32 to 7.27). For persons of non-heterosexual orientation, the chance of achieving ATHS value $\geq 106$ is 4.58 times greater than those of heterosexual orientation (OR 4.58, 95\% CI 1.76 to 11.89). A secular person's chances of achieving ATHS value $\geq 106$ was 10.70 times greater than a religious person's (OR 10.7, 95\% CI 4.55 to 25.17). A traditional person's chance of achieving ATHS value $\geq 106$ was 2.92 times greater than a religious person's (OR 2.92, 95\% CI 1.10 to 7.74 ).

These three variables accounted for $61 \%$ of the variance (see Table 6). 
Table 5 Comparative analysis of background characteristics and attitudes toward homosexuality

\begin{tabular}{|c|c|c|c|c|c|c|c|c|}
\hline & & \multicolumn{3}{|l|}{ ATHS score } & \multicolumn{4}{|c|}{ Levels of heterosexism } \\
\hline & & $<106(n=158)$ & $\begin{array}{l}\geq 106 \\
(n=225)\end{array}$ & $P$ value & $\begin{array}{l}1 / 2 \\
(n=268)\end{array}$ & $\begin{array}{l}3 \\
(n=32)\end{array}$ & $\begin{array}{l}4 / 5 \\
(n=83)\end{array}$ & p value \\
\hline \multirow[t]{2}{*}{$\operatorname{Sex}, \mathrm{n}(\%)^{\mathrm{a}}$} & Male & $53(34)$ & $38(17)$ & $<0.01$ & $53(20)$ & $11(34)$ & $27(32)$ & 0.02 \\
\hline & Female & $105(66)$ & $187(83)$ & & $215(80)$ & $21(66)$ & $56(68)$ & \\
\hline \multirow[t]{2}{*}{ Gender, n (\%) ${ }^{\mathrm{a}}$} & Men & $54(34)$ & $39(17)$ & $<0.01$ & $55(21)$ & $11(34)$ & $27(32)$ & 0.03 \\
\hline & Women & $104(66)$ & $186(83)$ & & $213(79)$ & $21(66)$ & $56(68)$ & \\
\hline \multirow[t]{2}{*}{ Education MA/PhD, n (\%) ${ }^{\mathrm{a}}$} & Yes & $52(33)$ & $71(32)$ & 0.78 & $87(33)$ & $10(31)$ & $26(31)$ & 0.98 \\
\hline & No & $106(67)$ & $154(68)$ & & $181(67)$ & $22(69)$ & $57(69)$ & \\
\hline \multirow{2}{*}{$\begin{array}{l}\text { Place of residence, } \\
\mathrm{n}(\%)^{\mathrm{a}}\end{array}$} & Urban & $100(63)$ & $144(64)$ & 0.89 & $176(66)$ & $17(53)$ & $51(62)$ & 0.34 \\
\hline & & $58(37)$ & $81(36)$ & & $92(34)$ & $15(47)$ & $32(38)$ & \\
\hline \multirow[t]{2}{*}{ Sexual orientation, n (\%) } & Not LGB & $151(96)$ & $195(87)$ & $<0.01$ & $235(88)$ & $29(91)$ & $82(99)$ & 0.01 \\
\hline & LGB & $7(4)$ & $30(13)$ & & $33(12)$ & $3(9)$ & $1(1)$ & \\
\hline \multirow[t]{3}{*}{ Religiousness, $n(\%)^{b}$} & Secular & $89(56)$ & $195(87)$ & $<0.01$ & $216(80)$ & $18(56)$ & $50(60)$ & $<0.01$ \\
\hline & Traditional & $32(20)$ & $22(10)$ & & $31(12)$ & $6(19)$ & $17(21)$ & \\
\hline & Religious & $37(24)$ & $8(3)$ & & $21(8)$ & $8(25)$ & $16(19)$ & \\
\hline Age (years), mean $\pm S D^{c}$ & & $38.1 \pm 9.1$ & $39.8 \pm 9.0$ & 0.06 & $39.0 \pm 9.0$ & $38.2 \pm 9.3$ & $39.8 \pm 9.3$ & 0.6 \\
\hline Years of experience, mean $\pm S D^{c}$ & & $11.4 \pm 9.2$ & $12.8 \pm 9.4$ & 0.16 & $12.1 \pm 9.2$ & $11.91 \pm 9.6$ & $12.9 \pm 9.8$ & 0.6 \\
\hline
\end{tabular}

ATHS: Attitudes Toward Homosexuality Scale; SD: standard deviation; LGB: lesbian, gay, and bisexual

${ }^{a}$ Chi-square test, ${ }^{b}$ Wilcoxon and Kruskal-Wallis tests, ${ }^{c}$ t-test and univariate ANOVA

Table 6 Multivariance logistic regression analysis results for the prediction of Attitudes Toward Homosexuality Scale scores $\geq 106$, indicating a positive attitude (odds ratio, confidence interval)

\begin{tabular}{ll}
\hline & ATHS Score $(\geq \mathbf{1 0 6})$ \\
\hline Age & $1.08(0.98-1.19)$ \\
Gender (woman) & $4.11(2.32-7.27)^{* * *}$ \\
Sexual orientation (not heterosexual) & $4.58(1.76-11.89)^{* *}$ \\
Religiousness (secular) & $10.70(4.55-25.17)^{* * *}$ \\
Religiousness (traditional & $2.92(1.10-7.74)^{* *}$ \\
Years of experience & $0.93(0.85-1.03)$ \\
Educational level (not holding MA/PhD) & $1.23(0.72-2.07)$ \\
Place of residence (not urban) & $1.39(0.84-2.29)$ \\
Wald (df) & $61.3(8)^{* * *}$ \\
C statistic & 0.76 \\
\hline
\end{tabular}

${ }^{*} p$ value $<0.05,{ }^{* *} p$ value $<0.01,{ }^{* * *} p$ value $<0.0001$

\section{Discussion}

This is the first study that explores the attitudes of registered PTs in Israel toward people identifying as LGB. PTs in Israel demonstrated considerably positive attitudes toward LGB individuals, as reflected by their high ATHS scores. Few studies have focused on examining PTs' attitudes toward the LGBTI community [11-13]. Since none of these studies used the ATHS questionnaire, it is not possible to compare the results of the present study to them.
LGBTI individuals have reported inappropriate experiences in terms of their personal comfort, discriminative behavior, and professional understanding of their health needs during physiotherapy treatment [13]. Burch's study focusing on the perspective of PTs indicates tolerant attitudes toward LGB patients of spinal cord injuries [11]. Copti et.al. (2016) [12] recommended, in a position paper, to ensure training of sexual orientation diversity competency during the physiotherapy education programs including self-awareness of implicit and explicit bias toward the LGBTI community and the possible effect on their attitude and mode of treatment, appropriate usage of language, and learning the specific health needs. Similarly, Glick et.al (2020) [15] focused on the physiotherapy education curricula in the US regarding LGBTI health topics and recommended updating the existing curricula, and increasing the competency of the physiotherapy students to prevent discriminatory care.

ATHS scores in the present study were higher than those previously reported by Shilo [20], who targeted social work students in Israel. However, it is unlikely that this difference between studies is indicative of true differences in the attitudes of PTs versus social workers. In fact, previous studies consistently indicated more positive attitudes toward sexual minorities among social workers in comparison to other health professionals [7, $9,22]$. In general, changes such as secularization and the increased demand for individual equality might have increased acceptance of sexual diversity in various areas 
of life [23]; thus, the more positive attitudes reported in this study may reflect the progressive social, cultural, and legislative changes toward sexual minorities that have occurred in Israel since the publication of Shilo's study in 2004 [20].

The majority (97\%) of the participants reported low or very low levels of homophobia, thus indicating that they would not engage in overt activities against members of the LGB community. In contrast, $22 \%$ of the participants stated that they held negative opinions regarding LGB individuals, as reflected by high or very high levels of heterosexism. This disparity may be explained by considering the concepts of homophobia and heterosexism as two ends of a continuum representing negative attitudes and behaviors toward the LGB community [24]. While the high ATHS scores and low self-reported levels of homophobia may reflect participants' explicit attitudes, their responses to the question regarding heterosexism may be more representative of implicit attitudes, which are far less positive. Such a disparity between implicit and explicit attitudes toward the LGB community has been reported in previous studies, as well [25]. The survey was kept anonymous to encourage truthful and honest responses. Anonymity was particularly important to increase the responsiveness of PTs belonging to more traditional and religious sections of the population, where issues relating to the LGB community are still considered taboo. However, as the questionnaires were distributed through professional and formal channels, this may have led to participants feeling obliged to comply with societal expectations and the ethical codes of the physiotherapy profession, which stress a commitment to providing unbiased healthcare to all minority groups [17]. In addition, it is possible that the explicit nature of most questions led the responder to tone down their attitudes due to self-awareness and fear that negative attitudes towards the LGB community may be perceived by the researcher as backward. However, it is also likely that some of the more traditional PTs simply ignored the questionnaire as they may have considered it an issue that should remain taboo.

The current multivariant logistic regression analysis demonstrated that gender, sexual orientation, and religiousness are significantly predictable with attitudes toward LGB individuals, as reflected in the ATHS scores. Those results are consistent with previous studies [7, 26-29]. Gender has previously been shown to be a significant predictor of attitudes toward LGB individuals, with men exhibiting more homophobic attitudes [26]. Religion is another well-established predictor of negative attitudes toward LGB people, sexual prejudice, and acts of discrimination against the LGB community [26, 27]. Thus, religious healthcare professionals have been known to exhibit more negative attitudes toward LGB individuals [26, 28]. Previous studies also support the association between the sexual orientation of healthcare providers and their attitudes toward LGB individuals, with healthcare professionals who identify as heterosexuals reporting more negative implicit attitudes compared to sexual minority healthcare providers [7, 29].

The registered PTs participants in the current study were also asked about their source of knowledge about the LGB community. The findings of the study were that only $2 \%$ of the participants stated that they had no knowledge regarding the LGB community. Although this finding seems very promising, the source of this information was not professional based on the current results. Only $2 \%$ of the respondents reported having been introduced to this topic during their professional physiotherapy bachelor's or master's degrees. Furthermore, the majority of respondents $(66 \%)$ reported that the source of their knowledge was the media (e.g., social media, television, newspapers). The present study did not examine the relation between the PTs attitudes toward LGB individuals and their sources of knowledge regarding LGB individuals and types of acquaintance with an LGB individual. Further studies should address this point. Knowledge regarding sexual orientation has been demonstrated to be a crucial factor influencing professional healthcare providers' attitudes toward people identifying as LGB [30]. Previous studies indicate that the knowledge deficits of healthcare professionals may lead to failure to inquire about their patients' sexual orientation, gender identity, and sexual health [31]. Inequalities and disparities in the physical and mental health status of sexual and gender minorities and in health care as experienced by sexual and gender minorities are well documented [32]. This undesirable situation a product of knowledge deficit of healthcare professionals, misunderstanding and non-recognition of the unique needs of LGBTI individuals, institutional and personal discrimination and phobia, and stigmatization and negative attitude of health care professional [33]. These current results highlight the need to address the issue of knowledge deficit of healthcare professionals by updating the physiotherapy curriculum and designing postgraduate education courses that include knowledge regarding sexual orientation and its effect on mental and physical health issues as well as the specific needs of the LGB community.

Several study limitations must be considered. The questionnaires distributed in this study addressed only PTs' attitudes toward LGB individuals and not their attitudes toward a wider range of sexual and gender minorities. The attitudes presented here relate only to registered PTs in Israel. Therefore, the results may not be representative of PTs belonging to other countries and cultures. 
Finally, compliance percentages could not be calculated as the questionnaires were distributed online and the total number of PTs who chose not to complete the questionnaires could not be obtained Thus, our recruitment method (via social media and snowballing method) may have implications on the representativeness of the population of interest, increasing the possibility that those who felt particularly strongly about the topic were our primary respondents.

\section{Conclusions}

Registered PTs in Israel demonstrate favorable attitudes toward LGB individuals. PTs who identify as men, heterosexual, and religious or traditional are more likely to hold negative attitudes toward LGB individuals. Only $2 \%$ of the participants reported physiotherapy studies as a source of knowledge on sexual and gender minorities. Despite the relatively positive attitudes of PTs towards sexual minorities, reliable knowledge regarding the special health needs of sexual minorities should be addressed both during physiotherapy educational programs and in post graduate professional courses. Further studies are required to explore how implicit and explicit attitudes toward people identifying as LGB affect physiotherapy treatment quality.

\section{Acknowledgments}

We would like to thank Shiraz Vered from the Statistics Consulting Unit, University of Haifa, Haifa, Israel for the statical analysis.

\section{Authors' contributions}

MEG \& RK equal contribution in conceptualization, methodology, investigation, data analysis, writing-original draft preparation and writing-review and editing. All authors read and approved the final manuscript.

\section{Funding}

No funding or financial support was received.

\section{Availability of data and materials}

The data are available from the corresponding author on reasonable request.

\section{Declarations}

\section{Ethics approval and consent to participate}

This study was approved by the Ethics Committee at the Faculty of Social and Health Sciences, at the University of Haifa (number 19/388). Accompanying online instructions indicated that completing and sending the questionnaire was indicative of informed consent.

\section{Consent for publication}

Not applicable.

\section{Competing interests}

Both authors declare no conflict of interest.

Received: 10 February 2021 Accepted: 12 October 2021

Published online: 16 November 2021

\section{References}

1. Perales F. The health and wellbeing of Australian lesbian, gay and bisexual people: a systematic assessment using a longitudinal national sample.
Aust Nz J Publ Heal. 2018;43(3):281-7. https://doi.org/10.1111/1753-6405. 12855.

2. OECD. Foreword, Society at a glance. OECD social indicators. Paris, France: OECD Publishing. 2019;2019 https://doi.org/10.1787/89d03b34-en.

3. Valfort M. LGBTI in OECD countries: a review. OECD social, employment and migration working papers, no. 198. 2017. Paris, France: OECD Publishing https://doi.org/10.1787/d5d49711-en.

4. Hatzenbuehler ML. Structural stigma and the health of lesbian, gay, and bisexual populations. Curr Dir Psychol Sci. 2014;23(2):127-32 https://doi. org/10.1177/0963721414523775.

5. Dinkel S, Patzel B, McGuire MJ, Rolfs E, Purcell K. Measures of homophobia among nursing students and faculty: a Midwestern perspective. IJNES. 2007:4(1):Article 24 https://doi.org/10.2202/1548-923X.1491.

6. Kissinger DB, Lee $S M$, Twitty L, Kisner H. Impact of family environment on future mental health professionals' attitudes toward lesbians and gay men. J Homosex. 2009;56(7):894-920. https://doi.org/10.1080/00918 360903187853.

7. Sabin JA, Riskind RG, Nosek BA. Health care providers'implicit and explicit attitudes toward lesbian women and gay men. AJPH. 2015;105(9):1831-41.

8. Ensign KA, Yiamouyiannis A, White KM, Ridpath BD. Athletic trainers' attitudes toward lesbian, gay, and bisexual National Collegiate Athletic Association student-athletes. J Athl Train, 2011;46(1):69-75. https://doi. org/https://doi.org/10.4085/1062-6050-46.1.69.

9. Floyd J, Wofford L. A comparison of Attitudes toward the lesbian. Gay: Bisexual, and Transgender Populations; 2020. Retrieved from https:// repository.belmont.edu/dnpscholarlyprojects/27

10. Bartoş SE, Berger I, Hegarty P. Interventions to reduce sexual prejudice: a study-space analysis and meta-analytic review. J Sex Res 2014;51(4):363382. https://doi.org/https://doi.org/10.1080/00224499.2013.871625.

11. Burch A. Health care providers'knowledge, attitudes, and self-efficacy for working with patients with spinal cord injury who have diverse sexual orientations 2008;88(2):191-198. https://doi.org/10.2522/ptj.20060188.

12. Copti N, Shahriari R, Wanek L, Fitzsimmons A. Lesbian, gay, bisexual, and transgender inclusion in physical therapy: advocating for cultural competency in physical therapist education across the United States. J Phys Ther Educ. 2016;30(4):11-6.

13. Ross MH, Setchell J. People who identify as LGBTIQ + can experience assumptionsdiscomfort, some discrimination, and a lack of knowledge while attending physiotherapy: a survey. J Physiother 2019;65(2):99-105. https://doi.org/https://doi.org/10.1016/j.jphys.2019.02.002

14. Parameshwaran, V., Cockbain, B. C., Hillyard, M., \& Price, J. R. Is the lack of specific lesbian, gay, bisexual, transgender and queer/questioning (LGBTQ) health care education in medical school a cause for concern? Evidence from a survey of knowledge and practice among UK medical students. J Homosexuality.2017; 64(3), 367-381.

15. Glick JC, Leamy C, Molsberry AH, Kerfeld Cl. Moving toward equitable health Care for Lesbian, gay, bisexual, transgender, and queer patients: education and training in physical therapy education. J Physical Ther Educ. 2020;34(3):192-7.

16. American Physical Therapy Association. Code of ethics for the physical therapist. 2020. Retrieved from https://www.apta.org/apta-and-you/ leadership-and-governance/policies/code-of-ethics-for-the-physicaltherapist.

17. World physiotherapy. Ethical principles-Policy statement 2019. Retrieved from https://world.physio/sites/default/files/2020-04/PS-2019-Ethicalprinciples.pdf

18. Ben-Ari AT. Homosexuality and heterosexism: views from academics in the helping professions. Br J Soc Work. 2001;31(1):119-31.

19. Kite ME, Deaux D. Attitudes toward homosexuality: assessment and behavioral consequences. Basic Appl Soc Psych. 1986;7(2):137-62 https:// doi.org/10.1207/s15324834basp0702_4.

20. Shilo G. Attitudes toward homosexuality among social work students (Unpublished master's thesis). 2004. Tel Aviv University, Tel Aviv.

21. Eick U, Rubinstein T, Hertz S, Slater A. Changing attitudes of high school students in Israel toward homosexuality. J LGBT Youth 2016;13(1-2):192206. https://doi.org/10.1080/19361653.2015.1087930.

22. Nowaskie DZ, Patel AU, Fang RC. A multicenter, multidisciplinary evaluation of 1701 healthcare professional students' LGBT cultural competency: comparisons between dental, medical, occupational therapy, pharmacy, 
physical therapy, physician assistant, and social work students. PLoS One 2020;15(8):e0237670. http://doi.org/10.137/journal.pone.0237670

23. Vecho O, Poteat $V$, Schneider B. Adolescents' attitudes toward same-sex marriage and adoption in France. J GLBT Fam Stud. 2015;12(1):24-45. https://doi.org/10.1080/1550428X.2015.1040530.

24. Baker K, Beagan B. Making assumptions, making space: an anthropological critique of cultural competency and its relevance to queer patients. Med Anthropol Q. 2014;28(4):578-98 https://doi.org/10.1111/maq.12129.

25. Steffens MC. Implicit and explicit attitudes towards lesbians and gay men. J Homosex 2005;49(2):39-66. https://doi.org/https://doi.org/10.1300/ J082v49n02.

26. Dessel AB, Rodenborg N. Social workers and LGBT policies: attitude predictors and cultural competence course outcomes. Sex Res Social Policy 2017;14(1):17-31. http://doi.org/https://doi.org/10.1007/ s13178-016-0231-3

27. Jäckle S, Wenzelburger G. Religion, religiosity, and the attitudes toward homosexuality-a multilevel analysis of 79 countries. J Homosex. 2014;62(2):207-41. https://doi.org/10.1080/00918369.2014.969071.

28. Nye EA, Crossway A, Rogers SM, Games KE, Eberman LE. Lesbian, gay, bisexual, transgender, and queer patients: collegiate athletic trainers' perceptions. J Athl Train 2019;54(3):324-333. http://doi.org/https://doi. org/10.4085/1062-6050-259-17

29. Nathan ML, Ormond KE, Dial CM, Gamma A, Lunn MR. Genetic counselors' and genetic counseling students' implicit and explicit attitudes toward homosexuality. JOGC. 2018;28(1):91-101 https://doi.org/10.1007/ s10897-018-0295-8.

30. Braun HM, Ramirez D, Zahner GJ, Gillis-Buck EV, Sherrif H, Ferrone M. The LGBTQI health forum: an innovative interprofessional initiative to support curriculum reform. Med Educ Online. 2017;22(1):1306419. https://doi.org/ 10.1080/10872981.2017.1306419.

31. Rose D, Ussher JM, Perz J. Let's talk about gay sex: gay and bisexual men's sexual communication with healthcare professionals after prostate cancer. Eur J Cancer Care. 2017;26(1):e12469 https://doi.org/10.1111/ecc. 12469.

32. Pratt-Chapman ML, Alpert AB, Castillo DA. Health outcomes of sexual and gender minorities after cancer: a systematic review. Syst Rev. 2021;10(1):1-30 https://doi.org/10.1186/s13643-021-01707-4.

33. McGowan, Victoria J., Hayley J. Lowther, and Catherine Meads. "Life under COVID-19 for LGBT+ people in the UK: systematic review of UK research on the impact of COVID-19 on sexual and gender minority populations." BMJ Open 2021;e050092. https://doi.org/10.1136/bmjopen-2021-050092

\section{Publisher's Note}

Springer Nature remains neutral with regard to jurisdictional claims in published maps and institutional affiliations.
Ready to submit your research? Choose BMC and benefit from:

- fast, convenient online submission

- thorough peer review by experienced researchers in your field

- rapid publication on acceptance

- support for research data, including large and complex data types

- gold Open Access which fosters wider collaboration and increased citations

- maximum visibility for your research: over 100M website views per year

At BMC, research is always in progress.

Learn more biomedcentral.com/submissions 